\title{
ESPIONAGEM ESTADUNIDENSE SOBRE O BRASIL E O LEILÃO DO CAMPO DE LIBRA: UMA ANÁLISE GEOPOLÍTICA
}

\author{
Caroline Scotti Vilain ${ }^{1}$
}

RESUMO: O cenário geopolítico internacional atualmente está tensionado e entre essas tensões encontra-se as espionagens estadunidenses. Um dos países sujeitos à isso é o Brasil e, tal espionagem, está ligada intrinsecamente à descoberta de petróleo na região do Pré-sal. O campo de Libra é um dos alvos e, nesse interím, está ameaçado por interesses particulares, principalmente os do governo, no contexto de reeleição e superávit primário, e dos países que aqui possuem influência. Diversas consequências podem ser observadas, assim como especulações sobre consequências dependentes das futuras ações governamentais.

Palavras-chave: Petróleo; Espionagem estadunidense; Pré-sal; Campo de Libra;

\section{U.S. SPY ON BRAZIL AND AUCTION THE FIELD OF LIBRA: A GEOPOLITICAL ANALYSIS}

\begin{abstract}
The geopolitical international is currently strained, and among these tensions, is the U.S. espionage. One of the countries subject to this is Brazil and, this eavesdropping, is intrinsically linked to the discovery of oil in the region of the pre-salt. The Libra oil field is one of the targets and, in the meantime, is threatened by particular interests, especially those from the government, in the context of re-election and primary surplus, and from the countries that have influence here. Several consequences can be observed, as well as speculation about consequences dependent on future government actions.
\end{abstract}

Keywords: Oil; U.S. espionage; Pre-salt; Libra oil field.

\footnotetext{
${ }^{1}$ Aluna do Curso de Graduação em Relações Internacionais da UFSC. E-mail: cascotti@ hotmail.com.
}

Recebido em 09/10/2013

Aceito em: 23/10/2013 


\section{INTRODUÇÃO}

Diversas regiões no mundo atualmente são estratégicas para a geopolítica do petróleo, a economia e política que envolve a exploração, comercialização e estabelecimento de preços de um mineral indispensável ao ritmo de vida e crescimento econômico que se tem atualmente. Os Estados Unidos, China e Europa são dependentes do petróleo advindo de outros países, sendo os dois primeiros os maiores consumidores mundiais, fato que juntamente com o controle das reservas de petróleo e gás natural pelas Companhias Nacionais da OPEP, que não possuem interesse em um esgotamento rápido, resultem em um controle de produção e preços dos barris.

Nesse contexto geopolítico conturbado, insere-se o Brasil. Após a descoberta da camada do pré-sal em 2004, holofotes foram direcionados para nossa região. Adentrando nesse contexto, foi cada vez mais difícil para o governo de Barack Obama justificar suas ações de espionagem, em principal sobre o Brasil. As ações da Casa Branca acabaram sempre desmentidas por novas denúncias de Edward Snowden, ex-analista da Agência Nacional de Segurança dos EUA. A revelação de setembro de 2013 demoliu as garantias da Casa Branca de que não faz espionagem econômica. Porém, ela não só o fazia, como estava interessada na Petrobrás. Os americanos cobiçam a tecnologia brasileira para extrair petróleo em águas profundas e querem saber mais sobre as imensas reservas do pré-sal. Os escandalos atingiram em cheio as relações bilateirais Brasil-Eua, o que quase adiou a visita da presidente Dilma Rouseff à Washington em outubro de 2013. Também surgiram pressões para adiar o leilão dos direitos de exploração do Petróleo no campo de Libra, na Bacia de Santos, na região do pré-sal. O leilão foi marcado para outubro e empresas americanas interessaram-se a participar. A questão é: como o Brasil pode se proteger da poderosa máquina de espionagem dos EUA e como irá se comportar diante do petróleo? Afinal, ninguém mais acredita que tudo isso seja apenas para combater o terrorismo. A própria presidenta Dilma Roussef afirma 'O motivo não é segurança, mas interesses econômicos e estratégicos'. 


\section{CONTEXTO GEOPOLÍTICO REFERENTE AO PETRÓleO BRASILEIRO E O LEILÃO DO CAMPO DE LIBRA}

O petróleo foi no último século fonte de disputas, e ao mesmo tempo fonte de desenvolvimento, de ascensão na Divisão Internacional do trabalho e fonte de enriquecimento interno. A soberania maior que um povo pode ter é garantir o seu bem-estar a partir do seu trabalho, dos seus recursos naturais e de suas tecnologias. Portanto, o petróleo é um assunto que está em alta pauta no cenário atual.

Inicia-se esta análise pela retomada do crescimento norte-americano, o qual está extremamente apoiado em uma estratégia energética. O desenvolvimento do popular gás de xisto permitiu reduzir 1/3 das importações americanas de petróleo. No entanto, o petróleo continua ainda hoje com o preço elevado, da ordem de 100 dólares o barril, e a OPEP tem mostrado músculo, coordenação suficiente para jogar com a Rússia para mantê-lo nesse patamar. É evidente, então, que o Brasil e o México são vistos como dois atores que podem ajudar a quebrar a espinha dorsal da OPEP, se ficarem do lado errado. E esta é a previsão futura.

Essa previsão futura, porém, tem raízes submergidas no histórico brasileiro e em suas ações atuais coordenadas com esse passado. Através de um problema com bases no pós-milagre brasileiro, encontramo-nos em uma exasperação do desenvolvimento e falta de controle do centro de decisão da economia brasileira. As privatizações que ocorrem desde FHC, com seu modelo de concessão ao invés de partilha, algo utilizado no leste-asiático e que funcionou extremamente bem vem levando o Brasil para um alto déficit no Balanço de Pagamento, principalmente em Transações Correntes, sendo previsto um déficit de US\$80 bilhões para 2013. Este resultado estrutural deve-se às imensas remessas de lucros enviadas ao exterior, que por sua vez são resultado da desnacionalização das grandes empresas brasileiras, as quais já somam mais de 4000 desde FHC.

Este modelo pregado a partir dos anos 90 está se refletindo atualmente no cenário petrolífero brasileiro. Ao invés de praticarem modelos de partilha na exploração dos poços já encontrados antes da nova Lei 12.351/10, a qual aplica o modelo de partilha aos campos encontrados a partir daquela data na região do pré-sal, fecham-se concessões que retiram do povo brasileiro o controle sobre seus próprios recursos internos, o qual inclusive poderia ser uma 
Revista Economia e Desenvolvimento, v. 25, n. 2, 2013.

virada nos problemas sistêmicos do país. E, apesar de os atuais poços encontrados estarem sob regime de partilha, somente $15 \%$ dos royalties do petróleo permanecem para o Brasil, o resto é remetido às multinacionais envolvidas, contrastando com as explorações de outros países do mundo que permanecem com $80 \%$ dos royalties comumente. Neste quesito, já observa-se que não fazem diferença leis de utilização dos royalties integralmente para educação, saúde ou outra área. Uma ínfima parte do que se produz fica, e por ser ínfima, ela não traria grandes mudanças a longo prazo. Um exemplo é o campo de Libra, na Bacia dos Santos. Ele traria, nos próximos 35 anos, mais de US\$3,45 trilhões em petróleo, porém, permanece-se com um valor irrisório ao ponto de correspender a $0,6 \%$ do PIB atual.

Essa grande participação do capital estrangeiro (80\% dos nossos royalties) é suficiente inicialmente para mostrar a importância deste no cenário internacional. Acresce-se à isso as pressões externas para a presidenta Dilma abrir a exploração do petróleo para esse capital. O Congresso Mundial de Petróleo ocorrido em fevereiro de 2013, no Riocentro, um grande lobby pela reabertura dos leilões dos campos de petróleo, é grande exemplo dessa tendência. No encerramento deste Congresso, o ministro de Minas e Energias Edison Lobão declarou reaberto os leilões, cedendo então à essa pressão internacional. É provável também que a visita do vicepresidente americano Joe Biden, em maio de 2013, tenha objetivado exortar a presidenta a leiloar Libra e a presidente da Petrobrás, Graça Foster, a não se empenhar na aquisição desse campo.

Partindo para análise da espionagem norte-americana, observa-se que ela, sim, inclui objetivos econômicos e grande interesse pela Petrobrás. A falsidade do projeto do xisto americano veio à calhar para despistar a opinião pública internacional, fazendo com que se acreditasse que eles seriam autossuficientes por muito tempo. Porém, com o xisto, o tempo de autossuficiência seria de 10, 15 anos no máximo, logo voltando à sua grande dependência do petróleo. Portanto, o grande objetivo aqui, se não direto, seria fazer com o Brasil entrasse do lado dele como produtor de petróleo, fazendo frente à OPEP e baixando os preços do petróleo no mercado. Ao invés de nosso país entrar como grande produtor e beneficiário desse potencial, ele está mostrando cada vez mais inclinação à abandonar tudo isso em favor, como foi dito, de um superávit primário no Balança de Pagamentos, o qual seria irrisório comparado com os lucros futuros que poderiam gerar uma estatização desses recursos. 
Uma boa prova de tais fatos é o documento feito pelo presidente Barack Obama à Casa Branca sobre a Segurança Energética do País, em março de 2011. Uma passagem é bem elucidatória:

'I set this goal (reduzir a importação de petróleo em 1/3) knowing that we're still going to have to import some oil. It will remain an important part of our energy portfolio for quite some time, until we've gotten alternative energy strategies fully in force. And when it comes to the oil we import from other nations, obviously we've got to look at neighbors like Canada and Mexico that are stable and steady and reliable sources. We also have to look at other countries like Brazil. Part of the reason I went down there is to talk about energy with the Brazilians. They recently discovered significant new oil reserves, and we can share American technology and know-how with them as they develop these resources. But our best opportunities to enhance our energy security can be found in our own backyard -- because we boast one critical, renewable resource that the rest of the world can't match: American ingenuity. American ingenuity, American know-how.'

O grande objetivo norte-americano em relação ao Brasil é dividir sua tecnologia e knowhow a medida que nós desenvolvemos nosso recurso. Um tanto quanto ambicioso, não? Principalmente se vermos que eles nos veem como seu 'quintal', no qual podem se utilizar da ingenuidade presente aqui e então explorar essa grande, vultuosa oportunidade na área do petróleo, explorando-o e enfraquecendo o Brasil, levando a um futuro colapso certo, se este continuar se comportando como o vêm. Penso ser este documento a prova mais concreta do que foi argumentado anteriormente.

\section{ANÁLISE DA JURISPRUDÊNCIA REFERENTE AO CASO}

Em um contexto de preços baixos do barril de petróleo, grande incerteza na exploração dos campos petrolíferos e da avalanche neoliberal, a Lei 9.478/97 foi criada. Esta criou o modelo de concessão sobre o petróleo brasileiro e trouxe, entre seus marcos regulatórios, o Art. 26, o qual explicita que a propriedade dos bens será conferida ao concessionário, principalmente por, naquele contexto, não se dar a devida atenção ao petróleo e por a exploração do mesmo no país ser dispendiosa a ponto de correr-se altos riscos na sua aquisição.

Porém, tudo muda quando da descoberta do pré-sal e dos grandes campos de interesse nacional. Assim, surge a Lei 12.351/10, cujo Art. 12 rege que o Conselho Nacional de Política Energética proporá ao Presidente da República os casos em que, visando à preservação do interesse nacional e ao atendimento dos demais objetivos da política energética, a Petrobras será 
Revista Economia e Desenvolvimento, v. 25, n. 2, 2013.

contratada diretamente pela União para a exploração e produção de petróleo, de gás natural e de outros hidrocarbonetos fluidos sob o regime de partilha de produção, o que muda o marco regulatório do petróleo até então baseado nas normas de 1997. Atente-se ao fato de que, no caso de assegurar o interesse nacional, seria concedido exploração somente à Petrobrás, dispositivo esse que está sendo ferido exatamente pelo leilão do Campo de Libra.

Aprofundando melhor o caso, se observarmos o Art. $2^{\circ}$ do mesmo dispositivo, em seu inciso $\mathrm{V}$ define-se área estratégica como uma região de interesse para o desenvolvimento nacional (neste caso enquadrando-se como interesse nacional e, consequentemente, sendo protegida pela lei para exploração exclusiva pela Petrobrás, em regime de partilha), delimitada em ato do Poder Executivo, caracterizada pelo baixo risco exploratório e elevado potencial de produção de petróleo, de gás natural e de outros hidrocarbonetos fluidos. Não há dúvidas de que o Campo de Libra enquadra-se neste último contexto e, portanto, não poderia estar sendo leiloado de forma alguma. Fere-se o nosso regimento interno, fere-se o interesse nacional e, acima de tudo, destitui-se a população brasileira do que é seu, legitimamente.

\section{CONCLUSÃO}

Por fim, vejo um futuro extremamente incerto para o Brasil. Um desperdício, uma falta de projeto nacional visando o desenvolvimento do país. O petróleo seria o grande recurso capaz de aumentar nosso PIB suficientemente para sanar problemas estruturais como educação, saúde, defesa, podendo levar inclusive a reformas tributária, agrária, fiscal. Todo um potencial imenso está prestes a ser desperdiçado pela continuação de erros passados que continuam presentes, mostrando que o país está com dificuldades para aprender com seu próprio erro. Corremos o risco de fadar a população brasileira à estagnação, reprimarização e, principalmente, à um déficit crescente na Balança de Pagamentos, com um crescimento vultuoso das remessas de lucros ao exterior e da dívida externa pública. Mais uma vez, o Brasil, quintal da América, irá seguir seu mestre, líder constante, para um buraco, dessa vez mais fundo que os anteriores. Alinhar-se aos EUA, mesmo após o episódio da espionagem, ceder às suas pressões, será dessa vez um erro sem volta, um passo errado que pode fadar todas as próximas gerações do país.

Além disso, acresce-se a falta de respeito à jurisdição brasileira. Em um ato de privilégio de interesses enraigados internamente, até mesmo a Justiça Federal se corrompeu. Abafando o 
caso atrás de seu tapete de interesses, negou qualquer possibilidade de vetar-se o leilão do Campo de Libra. É um desacato à soberania do povo brasileiro sobre os seus próprios recursos, legitimado então pelo nosso judiciário, nosso ministro de Minas e Energia e nossa presidente. Há que se fazer fronte à isso, porém, até que ponto podemos lutar contra interesses reinantes a, simplesmente, mais de um século e meio?

\section{REFERÊNCIAS}

BARBOSA, Vanessa. Como o leilão do Campo de Libra virou um cabo de guerra. Disponível em: <http://exame.abril.com.br/meio-ambiente-e-energia/noticias/como-oleilao-de-libra-virou-um-campo-de-guerra $>$ Acesso em: 20 out. 2013.

BARROS, P. S.; SCHUTTE, G. R.; PINTO, L. F. S. Além da autossuficiência: o Brasil como protagonista no setor energético. Brasília: IPEA, 2012. (Textos para Discussão, n. 1.725).

BRASIL. Lei no 12.351, de 22 de dezembro de 2010. Dispõe sobre a exploração e a produção de petróleo, de gás natural e de outros hidrocarbonetos fluidos, sob o regime de partilha de produção, em áreas do pré-sal e em áreas estratégicas; cria o Fundo Social - FS e dispõe sobre sua estrutura e fontes de recursos; altera dispositivos da Lei no 9.478, de 6 de agosto de 1997; e dá outras providências. Brasília, 22 de dezembro de 2010.

CHANG, H.-J. Chutando a escada: a estratégia do desenvolvimento em perspectiva história. São Paulo: Editora UNESP, 2002.

D'ANDRADE, Wladimir; VIEIRA, Gabriela. País pode perder até R\$ 331 bi com Libra, diz Ildo Sauer. Disponível em: <http://exame.abril.com.br/economia/noticias/pais-pode-perder-ater-331-bi-com-libra-diz-ildo-sauer>. Acesso em: 18 out. 2013.

DORNELLES, F. Retrocesso no pré-sal. O Globo, 6 ago. 2009.

FOLHA DE SÃO PAULO. 'O leilão do campo de Libra representa um grande equívoco', aponta leitora. Disponível em: <http://www1.folha.uol.com.br/paineldoleitor/2013/10/1359344o-leilao-do-campo-de-libra-representa-um-grande-equivoco-aponta-leitora.shtml >. Acesso em: 20 out. 2013.

G1. 'De qualquer maneira ocorrerá o leilão', diz Lobão sobre pré-sal. Disponível em: <http://g1.globo.com/economia/noticia/2013/10/nao-estamos-privatizando-o-petroleo-do-pre-saldiz-lobao-sobre-leilao.html>. Acesso em: 19 out. 2013. 
G1. Justiça já emitiu 18 decisões favoráveis ao leilão de Libra, diz AGU. Disponível em: <http://g1.globo.com/economia/noticia/2013/10/justica-ja-emitiu-18-decisoes-favoraveis-aoleilao-de-libra-diz-agu.html>. Acesso em: 20 out. 2013.

LESSA, C. O pré-sal e os maus brasileiros. Valor, 23 set. 2009.

LIMA, P. C. R. Pré-sal: o novo marco legal e a capitalização da Petrobras. Rio de Janeiro: Synergia, 2011.

MACEDO, Danilo. AGU diz que 18 das 23 ações para suspender leilão do Campo de Libra foram derrubadas. Disponível em: <http://agenciabrasil.ebc.com.br/noticia/2013-10-20/agudiz-que-18-das-23-acoes-para-suspender-leilao-do-campo-de-libra-foram-derrubadas $>$. Acesso em: 20 out. 2013.

MORAIS, José Mauro de. Petróleo em águas profundas : uma história tecnológica da Petrobras na exploração e produção offshore. Brasília: IPEA: Petrobras, 2013.424 p. : il., gráfs., mapas, tabs.

SCHUTTE, Giorgio R.. Panorama do Pré-Sal: Desafios e Oportunidades. Brasília: Ipea, 2012. (Texto para Discussão do IPEA, $\mathrm{n}^{\circ}$ 1791).

SCHUTTE, Giorgio R.. Neodesenvolvimento e abusca de uma nova inserção internacional. Brasília: IPEA, 2012. (Texto para Discussão do Ipea, $\mathrm{n}^{\circ}$ 1732).

VIOMUNDO. Http://www.viomundo.com.br/denuncias/ildo-sauer-chineses-vao-lucrarmuito-e-ainda-garantir-suprimento-seguro-de-petyr.html. Disponível em:

$<$ http://exame.abril.com.br/economia/noticias/pais-pode-perder-ate-r-331-bi-com-libra-diz-ildosauer>. Acesso em: 18 out. 2013.

UOL. A poucos dias do leilão, ANP diz que Libra pode produzir até $40 \%$ mais. Disponível em: <http://economia.uol.com.br/noticias/redacao/2013/10/18/ha-poucos-dias-do-leilao-anpsobe-em-40-a-previsao-de-producao-de-libra.htm>. Acesso em: 21 out. 2013. 